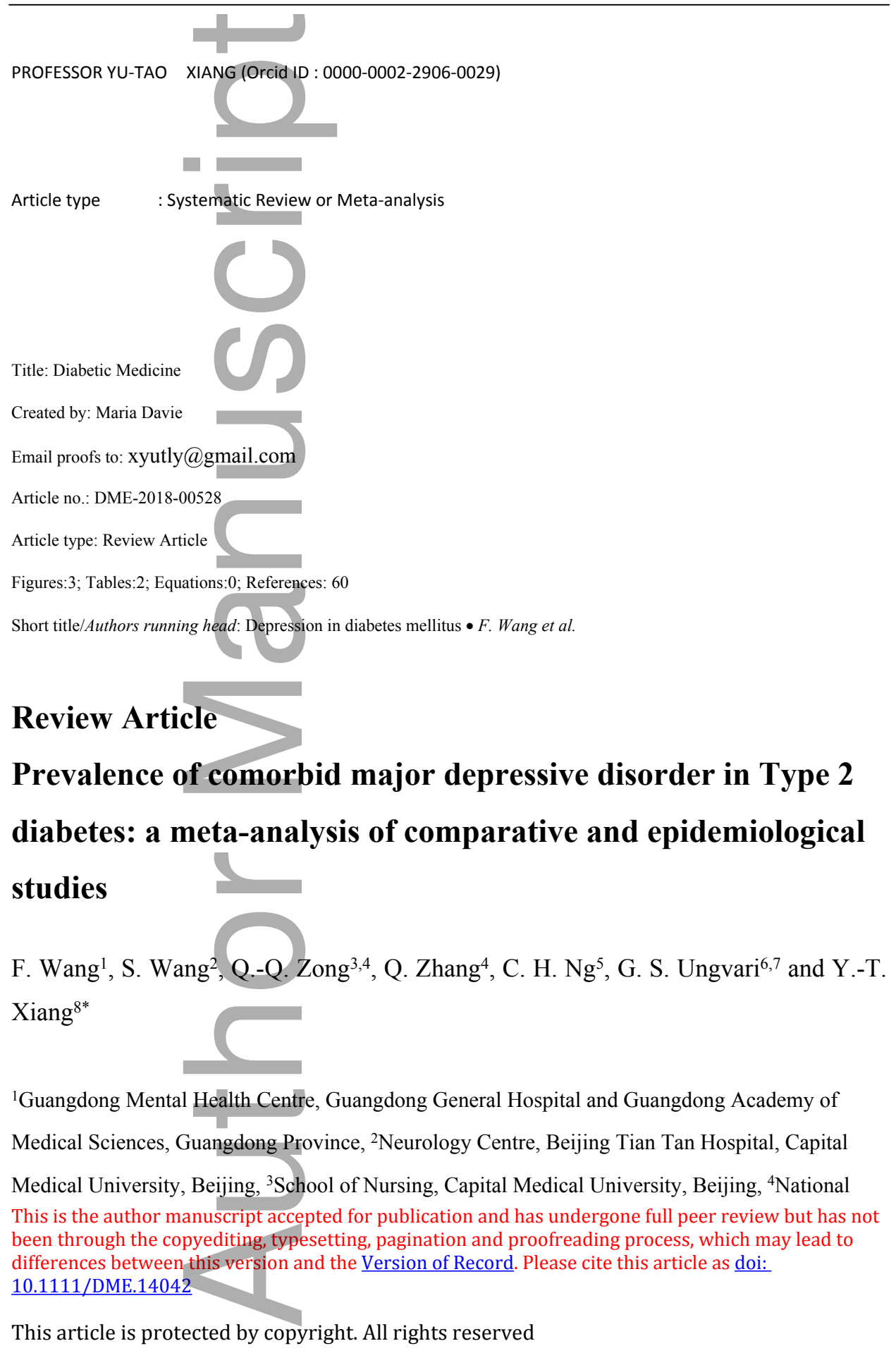


Clinical Research Centre for Mental Disorders and Beijing Key Laboratory of Mental Disorders, Beijing Anding Hospital and Advanced Innovation Centre for Human Brain Protection, Capital Medical University, Beijing, ${ }^{5}$ Department of Psychiatry, University of Melbourne, Melbourne, VIC., ${ }^{6}$ University of Notre Dame Australia, Fremantle, WA and ${ }^{7}$ Division of Psychiatry, School of Medicine, University of Western Australia, Perth, WA, Australia, ${ }^{8}$ Unit of Psychiatry, Faculty of Health Sciences, University of Macau, Macao SAR, China.

F.W., S.W. Q.-Q.Z. and Q.Z. contributed equally to the work.

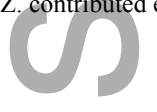

Correspondence to: Yu-Tao Xiang. E-mail: xyutly@gmail.com.
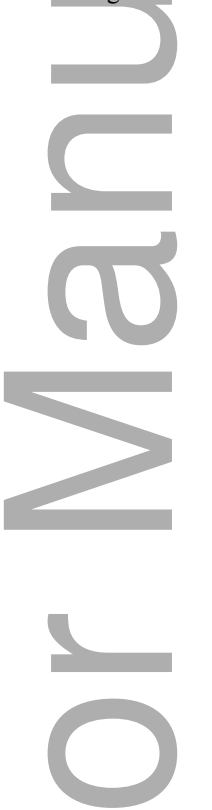

Abstract

Aims To examine the average point prevalence of major depressive disorder in people with Type 2 diabetes and its associated factors in a comprehensive meta-analysis.

Methods Two researchers independently conducted a systematic literature search of PubMed, EMBASE, PsycINFO and Cochrane databases. Studies reporting the prevalence of major depressive disorder in people with Type 2 diabetes were identified and analysed using a This article is protected by copyright. All rights reserved 
random-effects model.

Results A total of 26 studies meeting the inclusion criteria were included in the study. The point prevalence of major depressive disorder was $14.5 \%$ (95\% CI 7.9-25.3; $\left.I^{2}=99.65\right)$. People with Type 2 diabetes were more likely to have major depressive disorder compared with the general population (odds ratio 1.73, 95\% CI 1.38-2.16). Subgroup and meta-regression analyses showed that study site, diagnostic criteria and age significantly moderated the prevalence of major depressive disorder.

Conclusions In this meta-analysis, the average point prevalence of major depressive disorder in people with Type 2 diabetes was high. Routine screening and more effective interventions should be implemented for this population.

(Study registration no.: CRD42018096113)

\section{What's new?}

-This is the first meta-analysis to examine the prevalence of major depressive disorder in people with Type 2 diabetes in studies using standardized diagnostic instruments.

-People with Type 2 diabetes were more likely to have major depressive disorder compared with the general population.

-Routine screening and more effective treatments and interventions should be implemented for people with Type 2 diabetes and major depressive disorder.

\section{Introduction}

Type 2 diabetes mellitus is a common chronic disease that is prevalent worldwide [1]. Type 2 diabetes is associated with significant health complications, functional impairment and treatment burden [2]. The prevalence of Type 2 diabetes is rapidly growing [2,3], with the International Diabetes Federation estimating that the worldwide prevalence of diabetes mellitus will rise from 285 million in 2010 to 439 million by 2030 [4].

Major depressive disorder affects $\sim 7 \%$ of the general population in the USA [5]. Comorbid major depressive disorder is common in people with diabetes [6], reflecting the bi-directional relationship between the two conditions $[7,8]$. Depression in people with diabetes is associated with This article is protected by copyright. All rights reserved 
poor adherence to low-carbohydrate diet, exercise and medication treatment, and with negative health outcomes, lower quality of life, increased risk of suicide [9] and high economic cost [10]. In order to improve treatment access and delivery of health resources to address this comorbidity, it is crucial to examine the prevalence of major depressive disorder in people with Type 2 diabetes and its associated factors.

A study by Anderson et al. [7] found that Type 2 diabetes doubles the risk of depression (odds ratio 2.0, 95\% CI 1.8-2.2); however, that meta-analysis included both Type 1 and Type 2 diabetes, and major depressive disorder, minor and subsyndromal depression and depressive symptoms, which were identified with various screening instruments (such as the Geriatric Depression Scale, the Beck Depression Inventory and the Centre for Epidemiological Studies Depression Scale) and standardized diagnostic interviews [such as the Diagnostic Interview Schedule or the Structured Clinical Interview for Diagnostic and Statistical Manual of Mental Disorders (DSM), third edition, revised]. The use of different diagnostic instruments and measurements increased the heterogeneity of their sample. Furthermore, sophisticated analyses, such as subgroup, meta-regression and sensitivity analyses, were not performed. A subsequent systematic review [11] had similar limitations. Furthermore, these two review papers did not include two recently published studies $[12,13]$.

More recently, several studies have examined major depressive disorder in Type 2 diabetes using international diagnostic criteria, such as the DSM and the International Classification of Diseases (ICD), but their findings differed somewhat. For example, while the prevalence of major depressive disorder was $1.14 \%$ in people with Type 2 diabetes in the USA [14], the corresponding figure was $3.39 \%$ in Taiwan [15]. In an extensive search of the literature no meta-analysis of the prevalence of major depressive disorder in people with Type 2 diabetes was found.

The aim of the present comprehensive meta-analysis was to determine the average point prevalence of major depressive disorder in people with Type 2 diabetes and its associated factors. The odds ratios were also explored by comparing the prevalence of major depressive disorder between people with and without diabetes.

\section{Methods}

Search strategy and selection criteria

This article is protected by copyright. All rights reserved 
A flow chart of the literature search is shown in Fig. 1. Two researchers (Q.-Q.Z. and S.W.) independently conducted a systematic literature search of the PubMed, EMBASE, PsycINFO and Cochrane databases from their inception to 1 February 2018 using the following search terms: ('major depressi*') AND ('diabetes mellitus' OR 'diabetes' OR 'mellitus') AND ('epidemiology' OR 'prevalence'). The asterisk '*' is a commonly used wildcard symbol that broadens the search by finding words that start with the same letters. To avoid missing any additional studies, reference lists of reviews or meta-analyses were also searched manually. If more than one paper was published using the same dataset, only the one with the largest sample size was included in the meta-analysis.

According to the Preferred Reporting Item for Systemic Review and Meta-analyses (PRISMA) statement [16], the 'PICOS' acronym was used to define the inclusion criteria as follows: participants $(\mathrm{P})$, people with a diagnosis of Type 2 diabetes according to international or local diagnostic criteria, such as the WHO [17] or American Diabetes Association [18]; intervention (I), not applicable; comparison (C), people without diabetes in case-control studies; outcomes (O), not applicable; and study design (S): case-control or cohort studies (only baseline data were extracted from the latter) reporting the prevalence of major depressive disorder in people with Type 2 diabetes or any information that could generate such data. The diagnosis of major depressive disorder had to be established according to international or local (e.g. the Chinese Classification of Mental Disorders) diagnostic criteria using standardized diagnostic instruments, such as the Mini-International Neuropsychiatric Interview (MINI), the Structured Clinical Interview for DSM, third edition, revised, the Schedules for Clinical Assessment in Neuropsychiatry or the Composite International Diagnostic Interview. Studies involving Type 1 diabetes mellitus, pregnant women or other special populations were excluded. Studies that only reported the prevalence of depressive symptoms using screening questionnaires, reviews and case reports were also excluded.

\section{Selection of studies and data extraction}

Two researchers (Q.-Q.Z. and F.W.) independently screened the titles and abstracts of articles in the initial search results and read the full texts to select articles that fulfilled the inclusion criteria after removing duplicates. Any uncertainties were resolved by consensus or by discussion with a third reviewer (S.W.). The same two researchers independently performed data extraction using a standard data collection form. Information extracted included the following study characteristics: This article is protected by copyright. All rights reserved 
first author; publication year; study site; survey period; sampling method; sample size; demographic and clinical characteristics of the participants; diagnostic criteria applied; and prevalence of major depressive disorder.

\section{Quality assessment}

Two researchers (F.W. and Q.-Q.Z.) independently assessed the quality of included studies using a methodological quality assessment tool that comprises eight items [19]. Each study was scored from 0 to 8 . Scores of 7-8 were regarded as 'high quality', 4-6 as 'moderate quality' and 0-3 as 'low quality'. Any disagreement in the assessment was discussed and resolved by involving a third investigator (S.W.; Table S1).

\section{Statistical analysis}

Comprehensive Meta-Analysis software, version 2, was used to analyse the data. Pooled results were estimated using a random-effects model [20]. The $I^{2}$ statistic was used to assess the degree of heterogeneity across studies; $R>50 \%$ indicated high heterogeneity. The sources of high heterogeneity were examined in subgroup and meta-regression analyses. Sensitivity analysis was carried out by excluding each study one by one to detect outlying studies that could significantly affect the primary results. Publication bias was evaluated using funnel plots and Egger's test [21]. The significance level was set at 0.05 (two-sided).

\section{Results}

\section{Search results and characteristics of studies}

Of the 3393 studies initially identified in the literature search, 26 fulfilled the study entry criteria and were analysed (Fig. 1). Eight studies were cohort studies, 10 were case-control studies and the remaining eight were cross-sectional epidemiological studies. The sample size ranged from 61 to 778 123; three studies used the ICD, and the remainder used versions of the DSM to establish the diagnosis of major depressive disorder.

The study characteristics are shown in Table 1. The included studies were conducted between 1981 and 2015 in 15 countries in six continents: Asia (eight studies); Europe (three studies); North America (eight studies); South America (one study); Africa (three studies); and Oceania (three This article is protected by copyright. All rights reserved 
studies). The mean participant age was 57.2 years in the Type 2 diabetes groups and 46.8 years in the control groups.

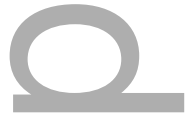

\section{Average point prevalence of major depressive disorder in Type 2 diabetes}

Based on the data from 26 studies comprising 96842 people with Type 2 diabetes, the average point prevalence of major depressive disorder was $14.5 \%$ [95\% CI 7.9-25.3; $I^{2}=99.65$ (Fig. 2)].

\section{Comparison between people with Type 2 diabetes and general population controls}

In 10 case-control studies, the point prevalence of major depressive disorder in both Type 2 diabetes and the general population groups was reported, contrasting 86262 people with Type 2 diabetes with 1237414 people in the general population. The prevalence of major depressive disorder was $9.2 \%\left(95 \%\right.$ CI $\left.3.2-23.7 ; P^{2}=99.2 \%\right)$ and $4.3 \%$ (95\% CI $\left.1.2-14.1 ; I^{2}=99.9 \%\right)$ in the Type 2 diabetes group and the general population, respectively. Compared with the general population, people with Type 2 diabetes were significantly more likely to have comorbid major depressive disorder [OR 1.73, 95\% CI 1.38-2.16; $P<0.001, I^{2}=81.63 \%$ (Fig. 3)].

\section{Subgroup, meta-regression and sensitivity analyses}

Table 2 shows the subgroup analyses of the point prevalence of major depressive disorder in Type 2 diabetes. Significant differences were found in diagnostic criteria $(P=0.001)$, study sites $(P=0.004)$ and study types $(P=0.02)$. The prevalence of major depressive disorder diagnosed with the DSM instrument $(17.5 \%)$ was higher than that diagnosed according to the ICD (3.1\%). Studies conducted in Africa (31.9\%) reported a higher prevalence of major depressive disorder than those from North and South America (12.7\%), Asia (16.9\%), Europe (17.3\%) and Oceania (4.7\%). The prevalence of major depressive disorder was lower in case-control studies $(7.5 \%)$ than in the other study types $(21.4 \%)$.

The prevalence of major depressive disorder in women and men with Type 2 diabetes was $24.0 \%$ and $15.8 \%$, respectively. Using a median splitting method for years (range: 1981-2016; $<2008$ vs $\geq 2008$ ), studies conducted in or after 2008 (17.6\%) reported a higher prevalence of major depressive disorder than those conducted before 2008 (11.5\%). The prevalence of major depressive disorder in studies conducted in hospitals/diabetes clinics/primary care facilities and those conducted in the community was $21.2 \%$ and $7.7 \%$, respectively. According to the WHO criteria This article is protected by copyright. All rights reserved 
from the year $2000, \mathrm{BMI} \geq 30 \mathrm{~kg} / \mathrm{m}^{2}$ defines obesity. Obese people with Type 2 diabetes also had a higher prevalence of major depressive disorder than those without obesity (14.7\% vs $7.9 \%)$. The prevalence of major depressive disorder in high- and moderate-quality studies was $16.8 \%$ and $12.8 \%$, respectively (Table 2); however, the differences in neither of these subgroup analyses reached significant levels (all $P$ values $>0.05$ ).

Meta-regression analysis showed a significant negative association between age and prevalence of major depressive disorder in Type 2 diabetes mellitus based on data from 17 studies (slope: $-0.12,95 \% \mathrm{CI}-0.13,-0.11 ; P<0.001)$.

\section{Quality assessment, publication bias and sensitivity analyses}

The mean (range) quality assessment score was 6.4 (5-8). Twelve (46.2\%) and 14 (53.8\%) studies were rated as being of high and moderate quality, respectively (Supporting Information). Figure S1 shows the funnel plot of the 26 studies that reported the point prevalence of major depressive disorder in Type 2 diabetes. Egger's test ( $t=1.88,95 \% \mathrm{CI}-0.98$ to $21.07 ; P=0.07)$ did not show publication bias. Figure S2 shows the funnel plot for the 10 case-control studies; Egger's test $(t=0.18,95 \% \mathrm{CI}-2.33$ to $2.72 ; P=0.86)$ did not show publication bias in studies comparing major depressive disorder between people with Type 2 diabetes and the general population. After removing each study sequentially, the results of the remaining studies remained consistent with the primary results (Fig. S3).

\section{Discussion}

To the best of our knowledge, the present study is the first meta-analysis to estimate the average point prevalence of major depressive disorder in people with Type 2 diabetes. The average point prevalence of major depressive disorder in people with Type 2 diabetes was $14.5 \%$, which is slightly higher than reported in a previous study (10.9\%) [7], but lower than in other meta-analyses $(17.6 \%,[11], 14.5 \%,[22])$. However, evaluation of depression was not uniform in these studies; depressive symptoms detected with different screening instruments and various types of depressive disorders, assessed by different diagnostic instruments, were included in the previous meta-analyses. By contrast, in the present meta-analysis, only people with major depressive disorder diagnosed according to operationalized diagnostic criteria were included, therefore, direct comparisons among This article is protected by copyright. All rights reserved 
studies should be made with caution. In the present study the higher prevalence of major depressive disorder found in people with Type 2 diabetes compared to the general population (odds ratio 1.73) is consistent with previous findings [22-24]. The impact of long-term treatment, medication-induced side effects and the high costs associated with diabetes are likely risk factors for depression [25].

Subgroup analyses showed significant differences in the prevalence of major depressive disorder across geographical areas; studies in Africa found people with Type 2 diabetes had the highest prevalence of major depressive disorder (31.9\%), followed by studies from Europe (17.3\%), Asia (16.9\%), America (12.7\%) and Oceania (4.7\%). Relatively poor economic status, low diabetes treatment rates, different cultural attitudes toward mental health, and limited access to health services in low-income countries increase the likelihood of major depressive disorder in people with Type 2 diabetes [26,27]. The prevalence of major depressive disorder also varies significantly according to different diagnostic criteria; the prevalence of major depressive disorder established using the DSM (17.5\%) was significantly higher compared to that established using ICD codes (3.1\%). Only three studies in the present meta-analysis applied ICD criteria, which could have led to bias in the pooled prevalence of major depressive disorder. The impact of diagnostic criteria on the prevalence of major depressive disorder warrants further research attention. The discrepancy in prevalence of major depressive disorder in Type 2 diabetes between case-control and other types of study is probably attributable to different sampling methods; random sampling was used in $70 \%$ of case-control studies, while the corresponding figure was only $25 \%$ in other study types.

A study conducted in 23 European countries found that women had almost twice the prevalence of major depressive disorder compared with men [28], which could be related, in part, to the effects of hormones in women [29]. A nonsignificant gender difference trend was observed previously in people with Type 2 diabetes [24] as well as in the present study (24.0\% in women and $15.8 \%$ in men).

Obesity is a significant contributing factor to the pathogenesis of depression [30]. Obesity increases insulin resistance [31], dysregulates the hypothalamic-pituitary-adrenal axis [32], and activates inflammatory pathways [33], all of which contribute to the development of depression [34]. Further, mental distress associated with weight-related stigma and discrimination could often precipitate depression in obese people [35]. Since obesity is common in diabetes, the prevalence of major depressive disorder in people with a BMI $\geq 30 \mathrm{~kg} / \mathrm{m}^{2}$ was higher than in those with a BMI This article is protected by copyright. All rights reserved 
$<30 \mathrm{~kg} / \mathrm{m}^{2}$ in the present meta-analysis.

The prevalence of major depressive disorder in Type 2 diabetes significantly increases with age [11]. With advancing age, people with Type 2 diabetes experience more chronic physical and mental comorbidities, disability and cognitive impairment, all of which increase the risk of depression. Unexpectedly, in the present study, older age was associated with decreased risk of depression. We hypothesize that certain variables, such as the psychological impact of Type 2 diabetes in younger patients, may moderate the association between age and the occurrence of major depressive disorder in Type 2 diabetes. This finding needs further exploration.

The results of the meta-analysis should be interpreted with caution because of its several methodological limitations. First, a number of factors relevant for the prevalence of major depressive disorder in Type 2 diabetes mellitus, such as the severity and treatment of Type 2 diabetes and social support, were not examined because of insufficient data. Second, the causal relationship between Type 2 diabetes and major depressive disorder could not be examined because most studies had a cross-sectional design. Third, only 10 case-control studies were available to calculate the odds ratios when comparing the prevalence of major depressive disorder between people with Type 2 diabetes and people without diabetes. Fourth, similar to other meta-analyses [36-39], a high level of heterogeneity was still present in the subgroup analyses, a shortcoming which is difficult to avoid in meta-analyses of observational surveys. The heterogeneity was probably attributable to differences among the included studies, such as different study aims and inclusion/exclusion criteria. Fifth, different periods of data collection across studies could impact on the point prevalence of major depressive disorder; however, meta-regression analysis did not reveal any significant moderating effect of the period of data collection on the primary results. The weight of included studies depends on several factors, such as sample size, the precision of the effect size estimate and the confidence intervals [40]. The weight of included studies in the meta-analysis was automatically calculated by the CMA programme, therefore, the contribution of each factor to the weight could not be examined.

In conclusion, the present meta-analysis of studies in the international literature found that the prevalence of major depressive disorder in people with Type 2 diabetes was common and significantly higher than that in the general population. Screening for depression should be incorporated in the management plan for Type 2 diabetes. Pharmacological treatment and psychosocial interventions should be considered for people with Type 2 diabetes and comorbid This article is protected by copyright. All rights reserved 
major depressive disorder.

\section{Funding sources}

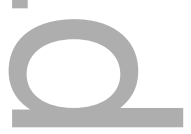

The study was supported by the University of Macau (MYRG2015-00230-FHS; MYRG2016-00005-FHS), the National Key Research and Development Programme of China (no. 2016YFC1307200), the Beijing Municipal Administration of Hospitals Incubating Programme (no. PX2016028) and the Beijing Municipal Administration of Hospitals' Ascent Plan (no. DFL20151801).

\section{Competing interests}

None declared.

\section{References}

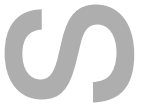

1. Guariguata L, Whiting DR, Hambleton I, Beagley J, Linnenkamp U, Shaw JE. Global estimates of diabetes prevalence for 2013 and projections for 2035. Diabetes Res Clin Pract 2014; 103:137-149.

2. Shaw JE, Sicree RA, Zimmet PZ. Global estimates of the prevalence of diabetes for 2010 and 2030. Diabetes Res Clin Pract 2010; 87:4-14.

3. Bensbaa S, Agerd L, Boujraf S, Araab C, Aalouane R, Rammouz I et al. Clinical assessment of depression and type 2 diabetes in Morocco: Economical and social components. J Neurosci Rural Pract 2014; 5:250-253.

4. Chen L, Magliano DJ, Zimmet PZ. The worldwide epidemiology of type 2 diabetes mellitus - present and future perspectives. Nat Rev Endocrinol 2012; 8:228.

5. Kessler RC, Berglund P, Demler O, Jin R, Koretz D, Merikangas KR et al. The epidemiology of major depressive disorder: results from the National Comorbidity Survey Replication (NCS-R). JAMA 2003; 289:3095-3105.

6. Bryan CJ, Songer TJ, Brooks MM, Thase ME, Gaynes BN, Klinkman M et al. A comparison of baseline sociodemographic and clinical characteristics between major depressive disorder patients with and without diabetes: a STAR*D report. $J$ Affect Disord 2008; 108:113-120.

7. Anderson RJ, Freedland KE, Clouse RE, Lustman PJ. The prevalence of comorbid depression in adults with diabetes: a meta-analysis. Diabetes Care 2001; 24:1069-1078.

8. Lloyd CE, Roy T, Nouwen A, Chauhan AM. Epidemiology of depression in diabetes: international and cross-cultural issues. $J$ Affect Disord 2012; 142 (Suppl.):S22-29.

This article is protected by copyright. All rights reserved 
9. Bogner HR, Morales KH, Post EP, Bruce ML. Diabetes, depression, and death: a randomized controlled trial of a depression treatment program for older adults based in primary care (PROSPECT). Diabetes Care 2007; 30:3005-3010. 10. Egede LE, Zheng D. Independent factors associated with major depressive disorder in a national sample of individuals with diabetes. Diabetes Care 2003; 26:104-111.

11. Roy T, Lloyd CE. Epidemiology of depression and diabetes: a systematic review. J Affect Disord 2012; 142:S8-S21.

12. Alvarez A, Faccioli J, Guinzbourg M, Castex MM, Bayon C, Masson W et al. Endocrine and inflammatory profiles in type 2 diabetic patients with and without major depressive disorder. BMC Res Notes 2013; 6:61.

13. Badawi G, Page V, Smith KJ, Gariepy G, Malla A, Wang J et al. Self-rated health: a predictor for the three year incidence of major depression in individuals with Type II diabetes. J Affect Disord 2013; 145:100-105.

14. Golden SH, Shah N, Naqibuddin M, Payne JL, Hill-Briggs F, Wand GS et al. The Prevalence and Specificity of Depression Diagnosis in a Clinic-Based Population of Adults With Type 2 Diabetes Mellitus. Psychosomatics 2017; 58:28-37.

15. Huang CJ, Lin CH, Lee MH, Chang KP, Chiu HC. Prevalence and incidence of diagnosed depression disorders in patients with diabetes: a national population-based cohort study. Gen Hosp Psychiatry 2012; 34:242-248.

16. Moher D, Liberati A, Tetzlaff J, Altman DG; PRISMA Group. Preferred reporting items for systematic reviews and meta-analyses: the PRISMA statement. PLoS Med 2009; 6:e1000097.

17. WHO. Definition, diagnosis and classification of diabetes mellitus and its complications: report of a WHO consultation. Part 1, Diagnosis and classification of diabetes mellitus. Geneva: WHO,1999.

18. Gabir MM, Hanson RL, Dabelea D, Imperatore G, Roumain J, Bennett PH et al. The 1997 American Diabetes Association and 1999 World Health Organization criteria for hyperglycemia in the diagnosis and prediction of diabetes. Diabetes Care 2000; 23:1108-1112.

19. Boyle MH. Guidelines for evaluating prevalence studies. Evid Based Ment Health 1998; 1:37-40.

20. Higgins JP, Thompson SG, Deeks JJ, Altman DG. Measuring inconsistency in meta-analyses. BMJ 2003; 327:557.

21. Egger M, Smith GD, Schneider M, Minder C. Bias in meta-analysis detected by a simple, graphical test. BMJ 1997; 315:629-634.

22. Ali S, Stone M, Peters J, Davies M, Khunti K. The prevalence of co-morbid depression in adults with Type 2 diabetes: a systematic review and meta-analysis. Diabet Med 2006; 23:1165-1173.

23. Mezuk B, Chen Y, Yu C, Guo Y, Bian Z, Collins R et al. Depression, anxiety, and prevalent diabetes in the Chinese population: findings from the China Kadoorie Biobank of 0.5 million people. J Psychosom Res 2013; 75:511-517.

This article is protected by copyright. All rights reserved 
24. Huang CJ, Hsieh HM, Tu HP, Jiang HJ, Wang PW, Lin CH. Major depressive disorder in patients with type 2 diabetes mellitus: Prevalence and clinical characteristics. J Affect Disord 2017; 227:141-148.

25. Semenkovich K, Brown ME, Svrakic DM, Lustman PJ. Depression in type 2 diabetes mellitus: prevalence, impact, and treatment. Drugs 2015; 75:577-587.

26. Ferrari A, Somerville A, Baxter A, Norman R, Patten S, Vos T et al. Global variation in the prevalence and incidence of major depressive disorder: a systematic review of the epidemiological literature. Psychol Med 2013; 43:471-481.

27. Kleinman A. Culture and depression. N Engl J Med 2004; 351:951-953.

28. Van de Velde S, Bracke P, Levecque K. Gender differences in depression in 23 European countries. Cross-national variation in the gender gap in depression. Soc Sci Med 2010; 71:305-313.

29. Parker G, Brotchie H. Gender differences in depression. Int Rev Psychiatry 2010; 22:429-436.

30. Luppino FS, de Wit LM, Bouvy PF, Stijnen T, Cuijpers P, Penninx BW et al. Overweight, obesity, and depression: a systematic review and meta-analysis of longitudinal studies. Arch Gen Psychiatry 2010; 67:220-229.

31. Lee WJ, Lee YC, Ser KH, Chen JC, Chen SC. Improvement of insulin resistance after obesity surgery: a comparison of gastric banding and bypass procedures. Obes Surg 2008; 18:1119-1125.

32. Pasquali R, Vicennati V. Activity of the hypothalamic-pituitary-adrenal axis in different obesity phenotypes. Int $J$ Obes Relat Metab Disord 2000; 24 (Suppl. 2):S47-49.

33. Shoelson SE, Herrero L, Naaz A. Obesity, inflammation, and insulin resistance. Gastroenterology 2007; 132:2169-2180.

34. Huber JD. Diabetes, cognitive function, and the blood-brain barrier. Curr Pharm Des 2008; 14:1594-1600.

35. Atlantis E, Ball K. Association between weight perception and psychological distress. Int J Obes 2008; 32:715-721.

36. Winsper C, Ganapathy R, Marwaha S, Large M, Birchwood M, Singh SP. A systematic review and meta-regression analysis of aggression during the first episode of psychosis. Acta Psychiatr Scand 2013; 128:413-421.

37. Long J, Huang G, Liang W, Liang B, Chen Q, Xie J et al. The prevalence of schizophrenia in mainland China: evidence from epidemiological surveys. Acta Psychiatr Scand 2014; 130:244-256.

38. Li Y, Cao XL, Zhong BL, Ungvari GS, Chiu HF, Lai KY et al. Smoking in male patients with schizophrenia in China: A meta-analysis. Drug Alcohol Depend 2016; 162:146-153.

39. Mata DA, Ramos MA, Bansal N, Khan R, Guille C, Di Angelantonio E et al. Prevalence of Depression and Depressive Symptoms Among Resident Physicians: A Systematic Review and Meta-analysis. JAMA 2015; 314:2373-2383.

This article is protected by copyright. All rights reserved 
40. Higgins J, Higgins J. Cochrane handbook for systematic reviews of interventions. Chichester: John Wiley \& Sons, 2008.

41. Eaton WW, Pratt L, Armenian H, Ford DE, Gallo J. Depression and Risk for Onset of Type II Diabetes: A prospective population-based study. Diabetes Care 1996; 19:1097-1102.

42. Saeed AK, Al-Dabbagh TQ. Type 2 diabetes and its association with hypertension and depression in an Iraqi population. Ann Saudi Med 2003; 23:254-259.

43. Thomas J, Jones G, Scarinci I, Brantley P. A descriptive and comparative study of the prevalence of depressive and anxiety disorders in low-income adults with type 2 diabetes and other chronic illnesses. Diabetes Care 2003; 26:2311-2317.

44. Lankarani MM, Assari S. Association between number of comorbid medical conditions and depression among individuals with diabetes; race and ethnic variations. J Diabetes Metab Disord 2015; 14:56.

45. Moreira RO, Papelbaum M, Fontenelle LF, Appolinario JC, Ellinger VCM, Coutinho WF et al. Comorbidity of psychiatric disorders and symmetric distal polyneuropathy among type II diabetic outpatients. Braz J Med Biol Res 2007; 40:269-275.

46. Fisher L, Skaff MM, Mullan JT, Arean P, Mohr D, Masharani U et al. Clinical depression versus distress among patients with type 2 diabetes: not just a question of semantics. Diabetes Care 2007; 30:542-548.

47. Aarts S, van den Akker M, van Boxtel MP, Jolles J, Winkens B, Metsemakers JF. Diabetes mellitus type II as a risk factor for depression: a lower than expected risk in a general practice setting. Eur J Epidemiol 2009; 24:641-648.

48. Agbir TM, Audu MD, Adebowale TO, Goar SG. Depression among medical outpatients with diabetes: a cross-sectional study at Jos University Teaching Hospital, Jos, Nigeria. Ann Afr Med 2010; 9:5-10.

49. Dirmaier J, Watzke B, Koch U, Schulz H, Lehnert H, Pieper L et al. Diabetes in primary care: Prospective associations between depression, nonadherence and glycemic control. Psychother Psychosom 2010; 79:172-178.

50. Bajaj S, Agarwal SK, Varma A, Singh VK. Association of depression and its relation with complications in newly diagnosed type 2 diabetes. Indian J EndocrinolMetab 2012; 16:759-763.

51. Baradaran HR, Mirghorbani SM, Javanbakht A, Yadollahi Z, Khamseh ME. Diabetes distress and its association with depression in patients with type 2 diabetes in iran. Int J Prev Med 2013; 4:580-584.

52. Coleman SM, Katon W, Lin E, Von Korff M. Depression and death in diabetes; 10-year follow-up of all-cause and cause-specific mortality in a diabetic cohort. Psychosomatics 2013; 54:428-436.

53. Das R, Singh OP, Mallick AK, Ali SN, Thakurta RG. Prevalence of depression in patients with type II diabetes mellitus and its impact on quality of life. Indian J Psychiatry 2013; 55:S52.

54. Abuhegazy H, Elkeshishi H, Farrag H, Saleh N. Depression and glycemic control in a sample of patients with type This article is protected by copyright. All rights reserved 
2 diabetes. Eur Neuropsychopharmacol 2014; 24:S480.

55. Musselman DL, Ziemer DC, McNutt MD, Seay JS, Royster EB, Larsen B et al. Depression, deficits in functional capacity, and impaired glycemic control in urban African Americans with type 2 diabetes. J Psychiatr Res 2014; 52:21-27.

56. Akena D, Kadama P, Ashaba S, Akello C, Kwesiga B, Rejani L et al. The association between depression, quality of life, and the health care expenditure of patients with diabetes mellitus in Uganda. $J$ Affect Disord 2015; 174:7-12.

57. Bruce D, Davis W, Hunter M, Peters K, Davis T, Starkstein S. Lifetime depression history and depression risk in type 2 diabetes: a case-control study. J Diabetes Complications 2016; 30: 38-42.

58. Van Dooren FEP, Denollet J, Verhey FRJ, Stehouwer CDA, Sep SJS, Henry RMA et al. Psychological and personality factors in type 2 diabetes mellitus, presenting the rationale and exploratory results from The Maastricht Study, a population-based cohort study. BMC Psychiatry 2016; 16:17.

59. Mushtaque A, Gulati R, Hossain MM, Azmi SA. Prevalence of depression in patients of type 2 diabetes mellitus: A cross sectional study in a tertiary care centre. Diabetes Metab Syndr 2016; 10:238-241.

60. Clarke TK, Obsteter J, Hall LS, Hayward C, Thomson PA, Smith BH et al. Investigating shared aetiology between type 2 diabetes and major depressive disorder in a population based cohort. Am J Med Genet B Neuropsychiatr Genet 2017; 174:227-234.

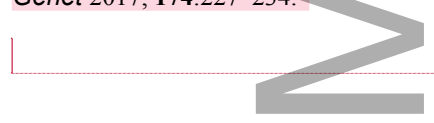

FIGURE 1 Flow chart of literature search.

FIGURE 2 Prevalence of major depressive disorder in people with Type 2 diabetes.

FIGURE 3 Comparison between the Type 2 diabetes group and the general population.

This article is protected by copyright. All rights reserved 


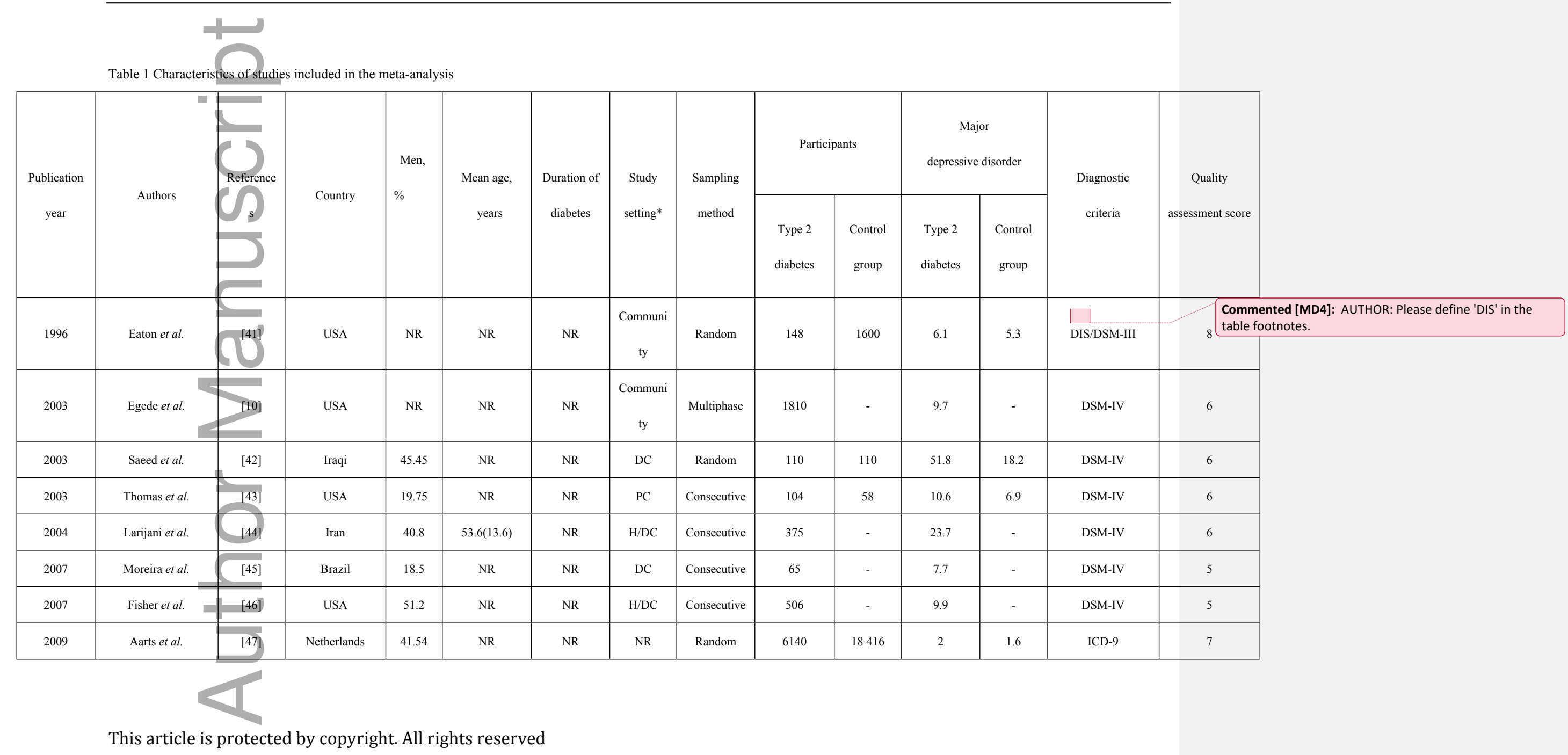




\begin{tabular}{|c|c|c|c|c|c|c|c|c|c|c|c|c|c|c|}
\hline 2010 & Agbir et al. & {$[48]$} & Nigeria & 40.99 & $\mathrm{NR}$ & $\mathrm{NR}$ & $\mathrm{H}$ & Consecutive & 160 & - & 19.4 & - & DSM-IV & 6 \\
\hline 2010 & Dirmaier et al. & [49] & Germany & 69.8 & $51.3(6.2)$ & $10.7(3.5)$ & $\mathrm{PC}$ & Consecutive & 866 & - & 11.8 & - & ICD-9 & 7 \\
\hline 2012 & Bajaj $e t a l$. & {$[50]$} & India & 50 & NR & NR & $\mathrm{H}$ & NR & 60 & 60 & 43.3 & 13.3 & DSM-IV & 6 \\
\hline 2013 & Alvarez et al. & & Italy & NR & NR & NR & $\mathrm{H} / \mathrm{DC}$ & NR & 61 & - & 34.4 & - & DSM-IV & 5 \\
\hline 2013 & Badawi et al. & & Canada & 43 & $57.8(9.86)$ & NR & $\mathrm{C}$ & Random & 1265 & - & 50.3 & - & DSM-IV & 8 \\
\hline 2013 & Baradaran et al. & [51] & Iran & 46.72 & $63.8(\mathrm{NR})$ & NR & $\mathrm{H} / \mathrm{DC}$ & Consecutive & 185 & - & 43.2 & - & DSM-IV & 6 \\
\hline 2013 & Coleman et al. & [52] & USA & 58.8 & $53.2(11.3)$ & NR & $\mathrm{H}$ & Random & 4128 & - & 12 & - & DSM-IV & 8 \\
\hline 2013 & Das et al. & 53] & India & 63.3 & NR & $\mathrm{NR}$ & $\mathrm{DC}$ & Consecutive & 195 & - & 46.2 & - & DSM-IV & 5 \\
\hline 2013 & Mezuk et al. & & China & 49.18 & $62(7)$ & NR & $\begin{array}{l}\text { Communi } \\
\text { ty }\end{array}$ & $\begin{array}{l}\text { Consecutive } \\
\text {, random }\end{array}$ & 15981 & 478039 & 0.9 & 0.6 & DSM-IV & 8 \\
\hline 2014 & Abuhegazy et al. & [54] & Saudi Arabia & 47 & $59.8(10.8)$ & NR & $\mathrm{DC}$ & $\begin{array}{l}\text { Consecutive } \\
\text {, random }\end{array}$ & 172 & - & 16.3 & - & DSM-IV & 5 \\
\hline 2014 & Musselman et al. & [55] & USA & 48.1 & $56.1(9.5)$ & $9.7(7.3)$ & $\mathrm{DC}$ & Random & 172 & - & 19 & - & DSM-IV & 6 \\
\hline 2015 & Akena et al. & [56] & Uganda & 51.9 & $63.4(13.4)$ & $9.6(9.4)$ & DC & Random & 437 & - & 34.8 & - & DSM-IV & 7 \\
\hline 2016 & Bruce $e t a l$. & [57] & Australia & 38 & $50(10)$ & 2.9 & $\begin{array}{c}\text { Communi } \\
\text { ty }\end{array}$ & Consecutive & 184 & 184 & 6 & 0.5 & DSM-IV & 7 \\
\hline 2016 & Van Dooren et al. & [58] & Netherlands & 35.2 & $51(14.1)$ & NR & DC & Random & 253 & 609 & 8.8 & 5.5 & DSM-IV & 8 \\
\hline
\end{tabular}

This article is protected by copyright. All rights reserved 


\begin{tabular}{|c|c|c|c|c|c|c|c|c|c|c|c|c|c|c|}
\hline 2016 & Mushtaque et al. & [59] & India & 50 & $\mathrm{NR}$ & $\mathrm{NR}$ & $\mathrm{DC}$ & NR & 80 & - & 38.8 & - & DSM-V & 5 \\
\hline 2017 & Golden et al. & [14] & USA & 54.76 & $\mathrm{NR}$ & NR & $\mathrm{DC}$ & NR & 103 & - & 8.7 & - & DSM-IV & 7 \\
\hline 2017 & Clarke et al. & {$[60]$} & UK & 40.93 & $\mathrm{NR}$ & NR & H & Random & 915 & 22582 & 14.2 & 11.4 & DSM-IV & 7 \\
\hline 2017 & Huang et al. & & China (Taiwan) & 48.45 & NR & $\mathrm{NR}$ & $\mathrm{NR}$ & Random & 62367 & 715756 & 1.3 & 0.7 & ICD-9 & 7 \\
\hline
\end{tabular}

DC, diabetes clinic; DSM, Diagnostic and Statistical Manual of Mental Disorders; DSM-III, DSM third edition; DSM-IV, DSM fourth edition; H, hospital; ICD-9, International Classification of Diseases, ninth revision; NR, not reported; PC, primary care.

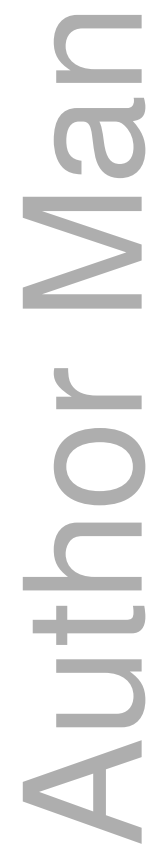

This article is protected by copyright. All rights reserved 


\begin{tabular}{|c|c|c|c|c|c|c|c|}
\hline Subgroup & Category (number of studies) & Events & Sample size & $\begin{array}{c}\text { Prevalence, } \%(95 \% \\
\text { CI })\end{array}$ & $I^{2}, \%$ & $\begin{array}{l}P \text { value within } \\
\text { subgroup }\end{array}$ & $\begin{array}{l}\mathrm{Q}(P \text { value }) \text { across } \\
\text { subgroups }\end{array}$ \\
\hline Gender & Men (12) & 995 & 46228 & $15.8(5.8-36.2)$ & 99.54 & 0.003 & \multirow{2}{*}{$0.44(0.51)$} \\
\hline & Women (12) & 1561 & 50363 & $24.0(9.9-47.6)$ & 99.65 & 0.032 & \\
\hline \multirow[t]{2}{*}{ Diagnostic criteria } & DSM (23) & 2331 & 27469 & $17.5(10.7-27.4)$ & 99.22 & $<0.001$ & \multirow{2}{*}{$6.87(0.001)$} \\
\hline & ICD (3) & 1002 & 69373 & $3.1(0.9-10.5)$ & 99.56 & $<0.001$ & \\
\hline Study site & Hospital/diabetes clinic (19) & 1462 & 8947 & $21.2(15.9-27.7)$ & 96.73 & $<0.001$ & \multirow{2}{*}{$1.18(0.28)$} \\
\hline- & Community (5) & 971 & 19388 & $7.7(1.0-40.0)$ & 99.82 & 0.02 & \\
\hline \multirow[t]{2}{*}{ Study area } & Africa (3) & 263 & 782 & $31.9(21.5-44.6)$ & 90.73 & 0.006 & \multirow{5}{*}{$15.60(0.004)$} \\
\hline & North and South America (9) & 1424 & 8301 & $12.7(6.2-24.0)$ & 99.16 & $<0.001$ & \\
\hline & Asia (8) & 1238 & 79340 & $16.9(4.5-46.4)$ & 99.71 & 0.031 & \\
\hline & Europe (3) & 253 & 1842 & $17.3(11.2-25.8)$ & 91.09 & $<0.001$ & \\
\hline & Oceania (3) & 155 & 6577 & $4.7(1.6-13.0)$ & 95.95 & $<0.001$ & \\
\hline $\mathrm{BMI}, \mathrm{kg} / \mathrm{m}^{2}$ & $<30.0(3)$ & 241 & 16419 & $7.9(0.4-64.5)$ & 99.72 & 0.12 & \multirow{2}{*}{$0.18(0.67)$} \\
\hline & $\geq 30.0(6)$ & 1322 & 7121 & $14.7(6.1-31.3)$ & 99.42 & $<0.001$ & \\
\hline
\end{tabular}

This article is protected by copyright. All rights reserved 


\begin{tabular}{|c|c|c|c|c|c|c|c|}
\hline \multicolumn{2}{|c|}{ Time of survey, year $\quad<2008$ (12) } & 1197 & 24425 & $11.5(6.1-20.6)$ & 99.04 & $<0.001$ & \multirow{2}{*}{$0.50(0.48)$} \\
\hline & $\geq 2008$ (14) & 2136 & 72417 & $17.6(6.1-\mathrm{F} 41.4)$ & 99.78 & 0.01 & \\
\hline \multirow[t]{2}{*}{ Study quality } & High quality (12) & 940 & 70175 & $16.8(6.1-38.6)$ & 99.80 & $<0.001$ & \multirow{2}{*}{$0.19(0.66)$} \\
\hline & Moderate quality (14) & 2393 & 26667 & $12.8(6.1-25.0)$ & 99.22 & 0.006 & \\
\hline \multirow[t]{2}{*}{ Study type } & Case-control (10) & 1350 & 86262 & $7.5(3.2-16.8)$ & 99.40 & $<0.001$ & \multirow[t]{2}{*}{$5.23(0.02)$} \\
\hline & Other (16) & 2028 & 10580 & $21.4(14.2-30.8)$ & 98.72 & $<0.001$ & \\
\hline
\end{tabular}

DSM, Diagnostic and Statistical Manual of Mental Disorders; ICD, International Classification of Diseases; Q, parameter estimates of subgroup comparisons.

\section{Supporting information}

Additional Supporting Information may be found in the online version of this article:

Table S1. Quality assessment of studies included in the meta-analysis.

Figure S1. Publication bias regarding the point prevalence of major depressive disorder in people with Type 2 diabetes.

Figure S2. Publication bias concerning the prevalence of major depressive disorder between people with Type 2 diabetes and the general population.

Figure S3. Results of the sensitivity analysis.

This article is protected by copyright. All rights reserved 


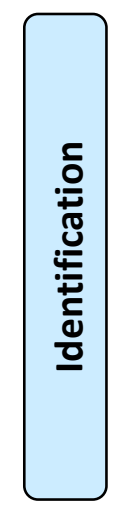

Records identified through database search

( $\mathrm{n}=3,393)$

PubMed ( $n=1,257)$; PsycINFO ( $n=632)$;

EMBASE $(n=1,314)$; Cochrane $(n=187)$;

Other sources $(n=3)$

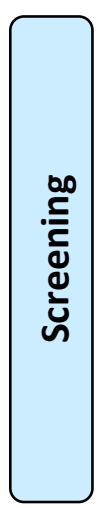

Records after duplicates removed

$$
(\mathrm{n}=2,609)
$$

Records excluded based on titles and/or abstracts

( $\mathrm{n}=2.543)$

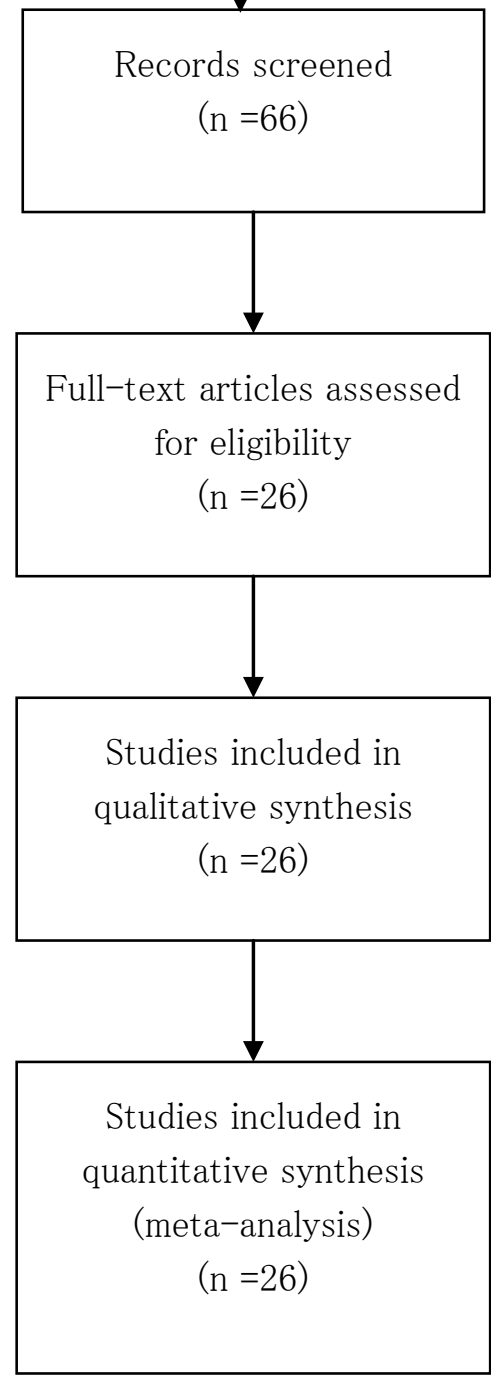




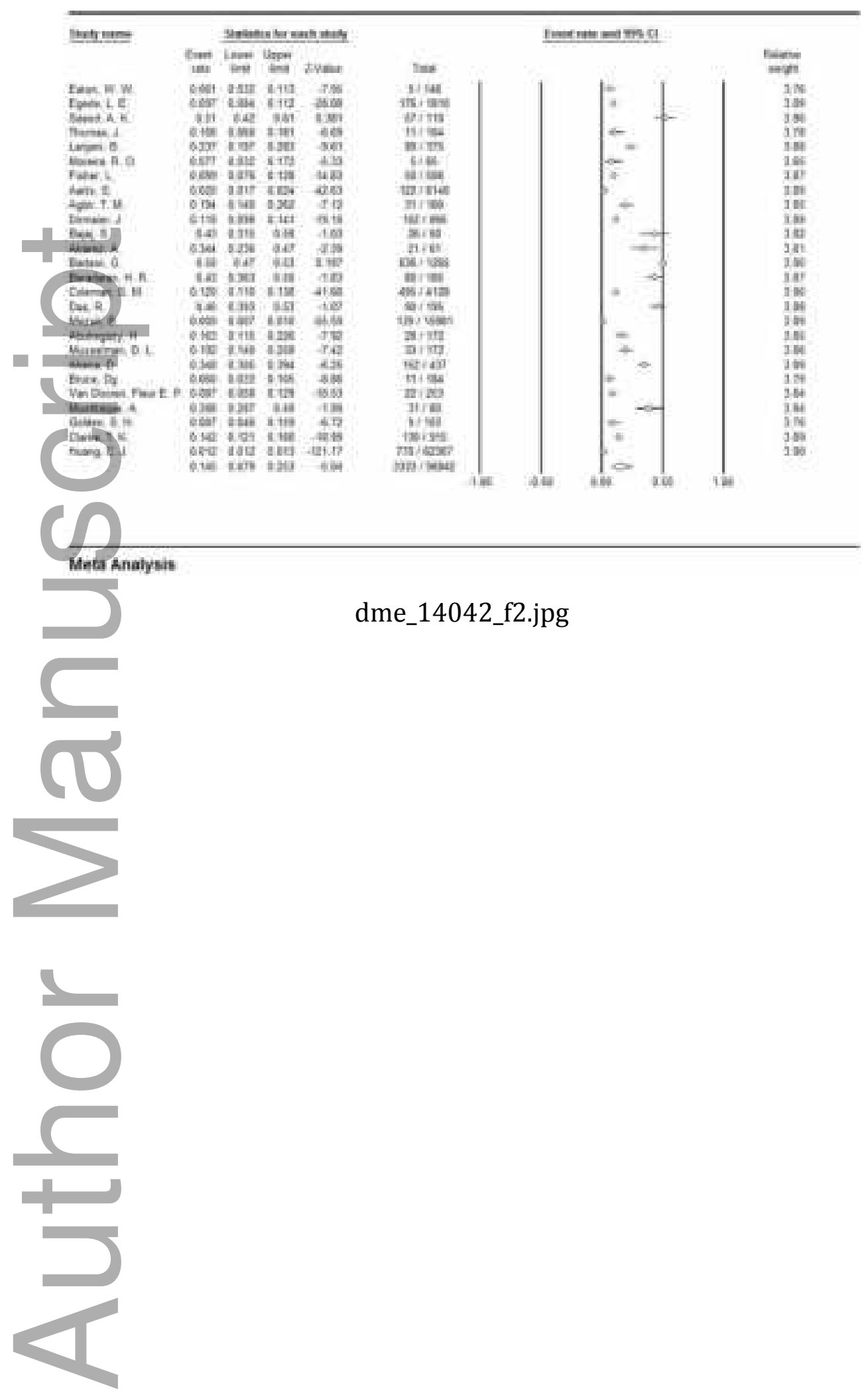

This article is protected by copyright. All rights reserved 


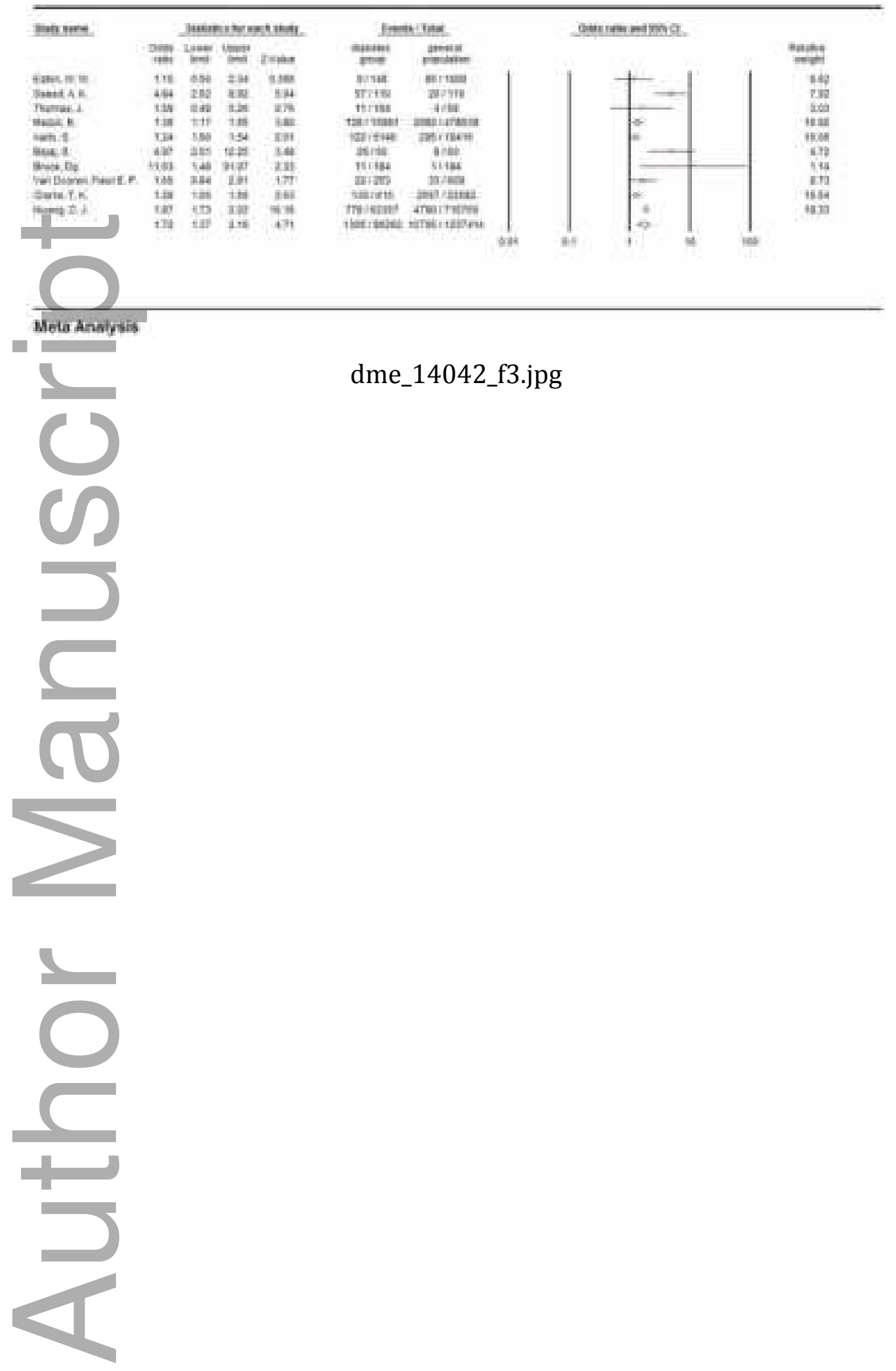

This article is protected by copyright. All rights reserved 


\section{University Library}

\section{- M M N E R VA A gateway to Melbourne's research publications}

Minerva Access is the Institutional Repository of The University of Melbourne

Author/s:

Wang, F;Wang, S;Zong, Q-Q;Zhang, Q;Ng, CH;Ungvari, GS;Xiang, Y-T

Title:

Prevalence of comorbid major depressive disorder in Type 2 diabetes: a meta-analysis of comparative and epidemiological studies

Date:

2019-07-01

Citation:

Wang, F., Wang, S., Zong, Q. -Q., Zhang, Q., Ng, C. H., Ungvari, G. S. \& Xiang, Y. -T. (2019). Prevalence of comorbid major depressive disorder in Type 2 diabetes: a meta-analysis of comparative and epidemiological studies. DIABETIC MEDICINE, 36 (8), pp.961-969. https:// doi.org/10.1111/dme.14042.

Persistent Link:

http://hdl.handle.net/11343/286103 